\title{
DETERMinants OF SUBJECTIVE WELL-BEING AMONG ROMANIAN OLDER ADULTS
}

\author{
AlEXANDRA CRISTINA SÎRBUi, MirCEA ASANDUlui ${ }^{\mathrm{ii}}$
}

\begin{abstract}
Due to population ageing, the analysis of the subjective well-being among older adults has received particular attention worldwide. In Romania this area of research is not very well studied and further investigation is needed. The purpose of this study is to analyze the determinants of subjective well-being of the Romanian older adults. Our empirical analysis is based on data from the Survey of Health, Ageing and Retirement in Europe. Using this we estimate ordinal logistic models to identify the main factors that explain subjective well-being.

Our empirical results show that higher levels of income, education and a good health have a significant positive effect on subjective well-being. Also, we show that being alone and not involved in a partnership negatively affects the well-being of older adults.
\end{abstract}

Keywords: subjective well-being, older adults, SHARE, life satisfaction, ordinal logit model.

\section{INTRODUCTION}

Population ageing is a worldwide phenomenon of concern, not limited to developed countries with high national income per capita, but also to middleincome countries. Romania is no exception. Due to the unprecedented demographic change, it is facing a deep socio-economic transformation. In the last decade, the demographic structure of the population shows an increase in the number of older people; this is caused by a higher level of life expectancy and decreasing fertility rate; these changes are the results of higher levels of education, economic control, and advanced technology.

\footnotetext{
${ }^{i}$ Doctoral School of Economics and Business Administration, „Alexandru Ioan Cuza University of Iaşi“, Faculty of Economics and Business Administration, Iaşi, Romania, sirbu.alexandra95@gmail.com

ii Alexandru Ioan Cuza University of Iaşi, Faculty of Economics and Business Administration, Iaşi, Romania, mircea.asandului@uaic.ro
} 
The population ageing crisis signaled to policy makers that measures for ensuring a higher level of well-being among the elderly are needed, as the pursuit of high well-being or happiness is ultimately an important goal of every human being and a target of high importance for every society (Hayo and Seifert, 2003; Diener and Seligman, 2004). In the context of higher life expectancy, by promoting and maintaining the well-being of older adults, the society is primarily the main beneficiary; as example some of them will still be active, work and contribute to the society and the cost associated with their healthcare will be reduced. In this manner the older adults will be able to support the society through their contributions and not the society will support them.

Subjective well-being, besides being a measure that can be used in the context of policy creation, can also be a determinant of public support for democratic regimes and market economies. Starting from all these, knowing and understanding the determinants of subjective well-being is a widely debated and researched topic. The literature presents various factors such as income, employment status, health status, age group, living arrangements, social ties, and religiosity as important determinants of subjective well-being (Fleche et al., 2011; Diener et al., 2013).

There is a quite low number of studies that have been conducted to identify the micro-level determinants of subjective well-being among older adults. Most of the studies on these determinants are carried out in developed countries; these countries have the financial resources to carry out such research, as opposed to developing countries like Romania. Another widely debated issue regarding the identification of determinants of well-being is that terms like happiness and life satisfaction are used interchangeably to assess a person's subjective well-being (Howell and Howell, 2008). Thus, to make a distinction between the two concepts, the OECD (2013) developed a guideline on measuring subjective well-being, suggesting that all aspects should be measured separately to allow a better understanding of the determinants.

Among the few studies on the subjective well-being of older adults in Romania is the one conducted by Precupetu (2016) which analyses the subjective well-being of two socio-structural groups (the poor and the precarious prosperous) in comparison with the group living in secure prosperity, using a sample aged between 18 and 65 years or more.

Given the lack of a comprehensive analysis in Romania on the determinants of subjective well-being among older adults and the limitations of existing research, this article aims to provide a more comprehensive picture of the 
determinants at micro level, using data from the Survey of Ageing, Retirement and Employment in Europe, a cross-national panel study of individuals aged 50 or over.

Based on the literature review, we would like to investigate several hypotheses, as follows:

H1: People with higher income show higher level of subjective wellbeing.

$\mathrm{H} 2$ : People with poor health tend to have a lower level of subjective well-being.

H3: There is a non-linear relationship between age and life satisfaction.

H4: People who are single are more likely to have lower life satisfaction.

H5: Older adults involved in work activities record higher levels of subjective well-being.

H6: Older adults who are living alone are more likely to be less satisfied with their lives.

H7: People with higher education level are more satisfied with their lives.

Regarding the structure of the article, the following two sections review the literature on subjective well-being and its determinants; after this, we provide a brief overview of the research design, focusing on data and methodology. Then, the results of data analysis are presented and discussed, and some conclusions about the determinants of subjective well-being of the Romanian's older adults are drawn.

\section{LITERATURE REVIEW}

\subsection{Defining and measuring subjective well-being}

A first aspect that needs to be addressed concerns what subjective well-being entails. Often it is used in relation to physical health, usually as a concept for psychological health. Secondly, it is seen as a subjective equivalent of objective indicators on quality of life, implying an individual judgement. From another point of view, defining subjective well-being is that, like its counterparts, madness, and illness, it is at least partly a social construct (Vanhoutte, 2012). Thus, what subjective well-being entails depends not only on a person's psychological perspective on life, but also on their position in society and the society in which they live. Therefore, any research on the nature of well-being must balance philosophical theory and empirical measurement (Sumner, 1999).

Regarding the definition of subjective well-being, OECD (2013) proposes a broad definition: "Good mental states, including all of the various evaluations, positive and negative, that people make of their lives and the affective reactions of people to their experiences". This definition primarily encompasses measures of 
how people live and evaluate their lives, namely that these evaluations are subjective because they are internally tested and not estimates of some external phenomenon. It also comprises three elements: life satisfaction in general, affect and eudaimonia. However, this paper examines only the first element which is a measurement of subjective well-being from the perspective of life satisfaction.

In terms of measuring life satisfaction in general, the OECD presents two approaches. The first one is the Cantril self-anchoring working scale, used, for example, in Gallup World Poll (Bjørnskov, 2010): "Please imagine a ladder with steps numbered from 0 at the bottom to 10 at the top. The top of the ladder represents the best possible life for you and the bottom of the ladder represents the worst possible life for you. If the upper step is 10 and the lower one is 0 , on which step of the ladder would you say you personally feel you stand at this time?". The second approach is the one used by World Values Survey (Bjørnskov, 2010) which involves asking a direct question about life satisfaction: „Taking all things together, how satisfied are you with your life these days? Using this card, where 1 means « completely dissatisfied 》 and 10 means 《 fully satisfied 》, where would you place your life satisfaction as a whole?"

\subsection{The determinants of subjective well-being}

After examining the literature on potential determinants of subjective wellbeing, we find that there are two main streams of research. The macro-level analysis focuses on understanding how variables such as national income, unemployment or inflation influence subjective well-being; in many cases the analysis focuses on the relationship between GDP and subjective well-being or on the Esterlin paradox (Degutis et al., 2010). The second type of analysis focuses on micro-level variables influencing subjective well-being such as income, education level, health status, etc (Bjornskov et al., 2008; Dolan et al., 2008; Peiro, 2006; Baird et al., 2010; Helliwell, 2003; Hudson, 2006; Busseri et al., 2009). In the present study, the focus will be on micro-level determinants.

Following the literature review, micro level determinants of subjective wellbeing among older adults can be grouped into several broad groups:

1. Demographic characteristics, such as age, gender, number of children, living area;

2. Socio-economic characteristics, such as income, education level, marital status, health status, employment status;

3. Social networks, such as caring for others, community involvement, seeing friends and relatives; 
4. Attitudes like trust in other people, religiousness.

Regarding the potential determinants of well-being, the literature reveals that there is a strong relationship between subjective well-being and the income level. Diener et al. (1999) conclude that there is a correlation between income and wellbeing in low-income countries and for the developed countries the situation is distinct. For these countries, once income reaches a threshold, further growth doesn't help in increasing the well-being (Clark et al., 2008).

Comparing the level of well-being among three groups of people (high, middle and low income), Cummins (2000) finds that "money buys happiness", especially for those who have low-income level. Likewise, Gildner et al. (2016) argues that income appears to influence well-being among older people; however, there is evidence that income is not a major determinant of subjective well-being among older adults (Wyshak, 2016).

A response to the influence of older adults' employment status on their wellbeing is not very clear stated, with some studies mentioning that self-employed respondents experience higher levels of happiness (Blanchflower and Oswald, 1998). On the other hand, the effect of unemployment on subjective well-being is clearly negative (Winkelmann, 2009). The impact of education varies from study to study, with some authors showing that there is no effect, while others show that subjective well-being is associated differently depending on the level of education (Clark and Oswald, 1994; Oswald, 1997; Blanchflower and Oswald, 2004). It is also mentioned that the level of education is correlated with income and health, so the latter should be controlled to fully capture the effect of education level (Bukenya et al., 2003).

Another interesting socio-economic determinant of subjective well-being is the role of health. Dolan et al. (2008) highlight that health status is strongly associated with subjective well-being. Haller and Hadler (2006) state that both good psychological and physical health have a strong and positive effect on subjective well-being, while chronic diseases negatively affect it (Easterlin, 2003).

Demographic variables can influence levels of well-being, age and gender being pertinent examples (Gerdtham and Johannesson, 1997). In general, women and men have similar levels of well-being, but this changes with age (Inglehart, 2002). A U-shaped distribution of well-being by age is described in the literature, with younger and older adults showing better levels of well-being than middle-aged adults (Blanchflower and Oswald 2008; Ferrer-i Carbonell and Gowdy, 2007).

Additional important factors that can also influence the level of subjective well-being of a person are marital status and living arrangements. The literature 
highlights that being alone has a negative effect on a person's well-being, as opposed to being in a partnership (Dolan et al., 2008; Stutzer and Frey, 2004). It has also been found that unlike less stable partnerships, stable partnerships are most often associated with similar levels of well-being for married people (Kahneman and Deaton, 2010). Living arrangements and family structure have been found to influence well-being among the elderly (Agrawal, 2012; Andrade and De Vos, 2016). Thus, older people living alone would record a lower level of well-being; it is also mentioned that they are more likely to have symptoms of depression than those who are living with a child.

Social participation is considered a very important factor in the well-being of older adults (Ashida and Heaney, 2008; Haslam et al., 2008). As people get older, their social relationships may diminish as friends or even partners may die and these changes have negative effects on well-being (Charles and Carstensen, 2010). On the other hand, Cornwell et al. (2008) find that as age increases, so do social relationships, volunteering and religious participation.

The impact of residence environment on well-being has not received much attention; we can assume that because the urban areas are more populated, they can provide goods and services that rural areas cannot provide efficiently, which could plausibly increase well-being. Gerdtham and Johannesson (1997) argue that the direct effect of urbanization on well-being is significantly negative. According to Brereton et al. (2011), even if rural areas present more limited accessibility to local services, the quieter and more peaceful environment leads to higher levels of life satisfaction.

\section{DATA AND METHODOLOGY}

The present study is done using data from the survey conducted by SHAREERIC - Survey of Health, Ageing and Retirement in Europe - European Research Infrastructure Consortium (Borch-Supan et al., 2013). SHARE consists of a longitudinal survey, collected every 2 years which includes data on socio-economic, lifestyle and health-related information for people aged 50 and over from more than 25 European Union countries plus Israel. So far 8 waves have been collected, the first started in 2004 and the last started in 2020 but ended quickly due to the COVID-19 pandemic. The dataset used in this study focuses on respondents aged 50 years and over who have the residence in Romania, from wave 8 of the survey.

We will measure the subjective well-being by the respondents' life satisfaction score: "On a scale of 0 to 10 , where 0 means total dissatisfaction and 10 means total satisfaction, how satisfied are you with your life?". Based on the literature review, we will try to explain this by socio-demographic characteristics 
like gender, living area, age, the number of children, marital status, level of education and living arrangements, level of income, the employment status at the moment of the interview, disability, self-assessment of health. Our sample consists 1157 Romanian older adults that have been questioned about several aspects of their life in 2020, just before the starting of the Corona virus pandemy.

Due to the ordinal nature of the dependent variable, we consider that the most appropiate way of conducting our analysis is by using the ordered logit model (McCullagh, 1980).

The ordinal logistic regression model can be defined as

$$
\operatorname{logit}(P(Y \leq j))=\beta_{j 0}+\beta_{j 1} x_{1}+\cdots+\beta_{j p} x_{p},
$$

Where $\beta_{\mathrm{j} 0}, \beta_{\mathrm{j} 1}, \cdots, \beta_{\mathrm{jp}}$ are the parameters (i.e., intercepts and slopes) of the predictors. The ordinal logit model can be used only for data which holds the proportional odds assumption. This assumes that the slopes are the same for all the categories. If the assumption is violated, the ordinal logit should be replaced by Generalized Ordinal Logistic Regression (Gujarati and Porter, 2009). An evaluation of this hypothesis is necessary as it is designed to assess whether the model is adequate.

\section{RESULTS}

After the data validation, we employ a descriptive statistics analysis. As mentioned before, in order to assess whether the model is adequate an evaluation of proportional odds hypothesis is necessary. Therefore, after testing this hypothesis was fulfilled $\left(\chi^{2}{ }_{\mathrm{LP}}=98.17, p=0.261\right)$, the odds for two outcomes were statistically similar, confirming the effectiveness of ordinal logistic regression in identifying subjective well-being determinants.

The estimated values for the dependent and control variables may be found in the Annex in Table 1. Our empirical results of the ordinal logistic regression presented in Table 2 show that subjective well-being of Romanian's older adults is significantly associated with marital status, level of education, income and selfassessment of health. According to the effect of marital status, the older adults who divorce or separate from partners are less likely to have higher scores on subjective well-being ( $\mathrm{p}<0.002$ ), this result confirming our fourth hypothesis $(\mathrm{H} 4)$ which states that the people who are single are more likely to have lower life satisfaction. 
Table 2 Ordinal Logistic Regression Estimates of the Determinants of Life Satisfaction

\begin{tabular}{|c|c|c|c|}
\hline Variables & $\boldsymbol{\beta}$ & SE & p-value \\
\hline Age & 0.001402 & 0.008262 & 0.865 \\
\hline \multicolumn{4}{|l|}{ Marital status (ref. Married/ Cohabitating) } \\
\hline Widowed & -0.2927471 & 0.178728 & 0.101 \\
\hline Separated/ Divorced & -0.766524 & 0.2498072 & $0.002^{* * *}$ \\
\hline \multicolumn{4}{|l|}{ Living arrangements (ref. Living alone) } \\
\hline Living with a family member & 0.1832468 & 0.1964996 & 0.351 \\
\hline \multicolumn{4}{|c|}{ Level of education (ref. Elementary school or less) } \\
\hline Middle school or unfinished high school & 0.2283911 & 0.1733975 & 0.188 \\
\hline Completed high school or post-secondary & 0.0710285 & 0.2016112 & 0.725 \\
\hline University studies & 0.6315563 & 0.3062284 & $0.039^{* *}$ \\
\hline \multicolumn{4}{|l|}{ Employment status (ref. Retired) } \\
\hline Employed & 0.1680222 & 0.1846814 & 0.363 \\
\hline Other inactive & 0.0205058 & 0.1702458 & 0.904 \\
\hline Income & 0.1896416 & 0.0704167 & $0.007^{* * *}$ \\
\hline \multicolumn{4}{|l|}{ Living area (ref. Rural) } \\
\hline Urban & -0.1754703 & 0.1247868 & 0.160 \\
\hline No. of children & 0.0514734 & 0.0395662 & 0.193 \\
\hline \multicolumn{4}{|l|}{ Disability $(r e f$. No $)$} \\
\hline Yes & -0.1666269 & 0.124071 & 0.179 \\
\hline \multicolumn{4}{|l|}{ Self-assessment of health (ref. Poor) } \\
\hline Fair & 0.6750929 & 0.1648297 & $0.000^{* * *}$ \\
\hline Good & 1.15116 & 0.1698887 & $0.000^{* * *}$ \\
\hline Very good & 1.967318 & 0.2400641 & $0.000^{* * *}$ \\
\hline Excellent & 2.617782 & 0.4641625 & $0.000^{* * *}$ \\
\hline Observations & 1157 & & \\
\hline LR chi2 & 197.14 & & $0.000^{* * *}$ \\
\hline
\end{tabular}

${ }^{* * * *} \mathrm{p}<0.001 ;{ }^{* *} \mathrm{p}<0.05$

Co-residence with family members is positively associated with subjective well-being measured by life satisfaction. Respondents who live with family members were more likely to report having a good or a very good life satisfaction, but this is not a significant predictor for Romanian's well-being which doesn't confirm our sixth the hypothesis.

The level of education and income have a positive and significant impact on Romanian older adults' life satisfaction. It can be noticed that the log-ratio in favor of higher level over a lower level of life satisfaction is, on average, 0,626 higher for 
respondents who have graduated university studies. Regarding the income, we found that it influences life satisfaction in old age, in contrast to the conventional wisdom according to which "money can't buy happiness". For every one-point increase on income there is a predicted increase of 0,192 in the log odds of a respondent being in a higher category on life satisfaction. This finding confirms our first and seventh hypothesis; we do not have empirical evidence that the Easterlin paradox exists in Romania, and income is still a strong factor that affects the respondents' subjective well-being.

Not all health variables indicate a significant impact on subjective wellbeing. There was no significant difference in the probability distribution of life satisfaction between respondents who don't have a disability and those who have. Even so, those who were less independent in their daily life activities were less likely to have higher scores on well-being. In contrast to this, in terms of self-rated health, respondents that have a very good health are more likely to record a much higher level of satisfaction than the ones with poor health. This is also the case for those with fair health, for whom the odds ratio in favor of higher level over a lower level of life satisfaction increase by 2,61 as opposed to those with poor health. All these results confirm our expectations expressed by hypothesis $\mathrm{H} 2$.

Among all categories (i.e., employed, other inactive), there are no significant differences in the probability distribution of life satisfaction between employment's categories; this doesn't confirm our hypothesis regarding that older adults' involvement in work activities increases their satisfaction with life.

Regarding the third hypothesis, we can say that age has not been found to be a predictor of subjective well-being among Romanian's elderly. We can't conclude if the relationship between Romanian older adults' subjective well-being and age is U-shaped as it is presented in the literature (Easterlin, 2006).

\section{Conclusions}

This study aims to examine the main determinates of subjective well-being of older adults. Our study contributes to empirical literature by dealing with the determinants of subjective well-being considering the Romanian older adults. We use micro-data to measure subjective well-being and we estimate an ordinal logit model to identify the main determinants of Romanian older adults' well-being.

Our empirical analysis shows that people who are divorced or separated perceived a lower subjective well-being level. This finding confirms the results obtained by Dolan et al. (2008) and Stutzer and Frey (2004), which have noticed 
that negative effects of being alone are more pronounced than those of living with a partner.

We also found that the factors that can increase the probability of life satisfaction for Romanian older adults are higher education, better health, and higher income. Having a good financial situation shows that, for the Romanians, the phrase "money buys happiness" applies. Consistent with previous studies, absolute and relative income play an important role in levels of life satisfaction (Easterlin, 2005; Ng and Diener, 2014).

We did not find any evidence to confirm the existence of a non-linear relationship between age and life satisfaction in the case of our sample; by analyzing this relationship we can say that the Romanian population is not experiencing an inevitable decline in life satisfaction simply because of increasing age. Analyzing the results, we can say that if older adults have a high level of income and good health, age has no effect on the overall level of subjective wellbeing. Also, hypotheses 5 and 6 are not confirmed.

One limitation of this study was the use of one single item for measurement of subjective well-being, thus for future development of the research we propose to measure subjective well-being using more than one dimension. Another next step would be to investigate if the relations found in Romania's case would hold true in other Eastern European countries.

Acknowledgements: The authors acknowledge financial support from the Romanian National Authority for Scientific Research and Innovation, CNCSUEFISCDI - Project PN-III-P4-ID-PCE- 2020-0929 Household Saving Behavior - A Socio-Economic Investigation from Households, Banks and Regulators Perspective. 


\section{REFERENCES}

1. Agrawal, S. (2012). Effect of living arrangement on the health status of elderly in india. Asian Population Studies, 8(1), 87-101. https://doi.org/10.1080/17441730.2012.646842, [Accessed 10.10.2021]

2. Andrade, F. C., and De Vos, S. (2016). An analysis of living arrangements among elderly women in Brazil. Encontro Da Associacao Brasileira de Estudos Populacionais, 14(8).

3. Ashida, S., and Heaney, C. A. (2008). Differential associations of social support and social connectedness with structural features of social networks and the health status of older adults. Journal of Aging and Health, 20(7), 872-893.

4. Baird, B., Lucas, R., and Donellan M. (2010). Life Satisfaction Across the life Span: Findings From two Nationally Representative Panel Studies. Social Indicators Research, 99, 183-203. http://dx.doi.org/10.1007/s11205-010-9584-9, [Accessed 04.05.2021]

5. Bjørnskov C (2010) How Comparable are the Gallup World Poll Life Satisfaction Data? Journal of Happiness Studies 11: 41-60. https://doi.org/10.1007/s10902-008-9121-6, [Accessed 15.05.2021]

6. Bjornskov, C., Dreher, A., and Fischer, J. (2008). Cross Country Determinants of Life Satisfaction: Exploring Different Determinants Across Groups in Society. Social Choice Welfare, 30, 119-173. http://dx.doi.org/10.1007/s00355-007-0225-4 , [Accessed 25.07.2021]

7. Blanchflower, D. G., and Oswald, A. J. (2008). Is well-being U-shaped over the life cycle? Social Science and Medicine, 66(8), 1733-1749.

8. Blanchflower, D., and Oswald, A. (2004). Well - Being Over Time in Britain and the USA. Journal of Public Economics, 88, 1359-1386. http://dx.doi.org/10.1016/S00472727(02)00168-8 [Accessed 07.08.2021]

9. Börsch-Supan, A. (2021). Survey of Health, Ageing and Retirement in Europe (SHARE) Wave 8. Release version: 1.0.0. SHARE-ERIC. Data set. DOI: 10.6103/SHARE.w8.100

10. Brereton, F., Bullock, C., Clinch, J. P., and Scott, M. (2011). Rural change and individual well-being. European Urban and Regional Studies, 18(2), 203-227. https://doi.org/10.1177/0969776411399346, [Accessed 19.07.2021]

11. Bukenya, J., Gebremedhin, T., and Schaeffer, P. (2003). Analysis of Rural Quality of Life and Health: a Spatial Approach. Economic Development Quarterly, 17, 280-293. http://dx.doi.org/10.1177/0891242403255325 , [Accessed 21.09.2021]

12. Busseri, M., Sadava, S., Molnar D., and DeCourville, N. (2009). A Person - Centered Approach to Subjective Well - Being. Journal of Happiness Studies, 10, 161-181. http://dx.doi.org/10.1007/s10902-007-9072-3, [Accessed 11.06.2021]

13. Charles S.T., Carstensen L.L. Social and emotional aging. Annual Review of Psychology. 2010; 61:383-409

14. Clark, A. E., and Oswald, A. J. (1994). Unhappiness and unemployment. Economic Journal, 104(424), 648-659.

15. Clark, A.E., Frijters, P. and Shields, M.A. (2008). Relative income, happiness and utility: an explanation for the Easterlin paradox and other puzzles. Journal of Economic Literature, 46(1), pp. 95-144. 
16. Cornwell, B., Laumann, E. O., and Schumm, L. P. (2008). The social connectedness of older adults: A national profile. American sociological review, 73(2), 185-203.

17. Cummins, R. A. (2000). Personal income and subjective well-being: A review. Journal of Happiness Studies, 1(2), 133-158.

18. Degutis, M., Urbonavicius, S., and Gaizutis, A. (2010). Relation between life Satisfaction and GDP in the European Union. Ekonomika, 89(1), 9-21

19. Diener E, Inglehart R, Tay L. Theory and validity of life satisfaction scales. Soc Indic Res 2013; 112:497-527.

20. Diener, E., and M. Seligman (2004). Beyond Money: Toward an Economy of Well Being. Psychological Science in the Public Interest, 5, 1-31. http://dx.doi.org/10.1111/j.0963-7214.2004.00501001.x

21. Diener, E., Suh, E. M., Lucas, R. E., and Smith, H. L. (1999). Subjective well-being: Three decades of progress. Psychological bulletin, 125(2), 276.

22. Dolan, P., Peasgood, T., and White, M. (2008). Do We Really Know What Makes us Happy? A Review of the Economic Literature on the Factors Associated With Subjective Well-Being. Journal of Economic Psychology, 29, 94-122. http://dx.doi.org/10.1016/j.joep.2007.09.001, [Accessed 17.06.2021]

23. Easterlin RA. Feeding the illusion of growth and happiness: a reply to hagerty and veenhoven. Soc Indic Res 2005;74:429-43

24. Easterlin, R. A. (2003). Explaining happiness. Proceedings of the National Academy of Sciences, 100(19), 11176-11183.

25. Easterlin, R. A. (2006). Life cycle happiness and its sources. Journal of Economic Psychology, doi:10.1016/j.joep.2006.05.002

26. Ferrer-i-Carbonell, A., and Gowdy, J. (2007). Environmental Degradation and Happiness. Ecological Economics, 60, 509-516. http://dx.doi.org/10.1016/j.ecolecon.2005.12.005, [Accessed 13.09.2021]

27. Fleche S, Smith C, Sorsa P. Exploring Determinants of Subjective Wellbeing in OECD Countries: Evidence from the World Value Survey. Paris OECD Economics Department Working Papers: OECD Publishing, 2011: 921.

28. Gerdtham, Ulf-G. and Johannesson, M. (1997). The relationship between happiness, health and socio-economic factors: results based on Swedish micro data. Department of Economics, Stockholm School of Economics, Stockholm, Sweden. (Working Paper Series in Economics and Finance no. 207).

29. Gildner, T. E., Liebert, M. A., Capistrant, B. D., D’Este, C., Snodgrass, J. J., and Kowal, P. (2016). Perceived Income Adequacy and Well-being Among Older Adults in Six Low- and Middle-Income Countries. The Journals of Gerontology Series B: Psychological Sciences and Social Sciences, O(0), gbw145. https://doi.org/10.1093/geronb/gbw145, [Accessed 03.06.2021]

30. Gujarati, D. N., and Porter, D. C. (2009). Basic econometrics. NY: McGraw-Hill Education.

31. Haller, M., and Hadler M. (2006). How Social Relations and Structures Can Produce Happiness and Unhappiness: an International Comparative Analysis. Social Indicators Research, 75, 169-216. http://dx.doi.org/10.1007/s11205-004-6297-y, [Accessed 28.06.2021]

32. Haslam, C., Holme, A., Haslam, S. A., Iyer, A., Jetten, J., and Williams, W. H. (2008). Maintaining group memberships: Social identity continuity predicts well-being after stroke. Neuropsychological rehabilitation, 18(5-6), 671-691. 
33. Hayo, B., and Seifert, W. (2003). "Subjective economic Well-Being in Eastern Europe". Journal of Economic Psychology, 24, 329-48. http://dx.doi.org/10.1016/S01674870(02)00173-3

34. Helliwell, J. F. (2003). How's Life? Combining Individual and National Variables to Explain Subjective Well-Being. Economic Modelling, 20, 31-360. http://dx.doi.org/10.1016/S0264-9993(02)00057-3, [Accessed 17.08.2021]

35. Howell RT, Howell CJ. The relation of economic status to subjective well-being in developing countries: a meta-analysis. Psychol Bull 2008; 134:536-60.

36. Hudson, J. (2006). Institutional Trust and Subjective Well-Being Across the EU. Kyklos, 59(1), 43-62. http://dx.doi.org/10.1111/j.1467-6435.2006.00319.x, [Accessed 09.05.2021]

37. Inglehart, R. (2002). Gender, aging, and subjective well-being. International Journal of Comparative Sociology, 43(3-5), 391-408.

38. Kahneman, D., and Deaton, A. (2010). High income improves evaluation of life but not emotional well-being. Proceedings of the National Academy of Sciences of the United States of America, 107(38), 16489- 16493. doi: 10.1073/pnas.1011492107

39. McCullagh, P. (1980). Regression models for ordinal data. Journal of the Royal Statistical Society: Series B (Methodological), 42(2), 109-127.

40. Ng W, Diener E. What matters to the rich and the poor? Subjective well-being, financial satisfaction, and postmaterialist needs across the world. J Pers Soc Psychol 2014; 107:326-38..

41. Ng, W., and Diener, E. (2018). Affluence and Subjective Well-Being: Does Income Inequality Moderate their Associations? Applied Research in Quality of Life, 1-16.

42. OECD (2013) Guidelines on measuring subjective well-being http://dx.doi.org/10.1787/9789264191655-en, [Accessed 10.08.2021]

43. Oswald, A. J. (1997). Happiness and economic performance*. The Economic Journal, 107(445), 1815-1831.

44. Peiro, A. (2006). Happiness, Satisfaction and Socio - Economic Conditions: Some International Evidence. The Journal of Socio - Economics, 35, 348-365. http://dx.doi.org/10.1016/j.socec.2005.11.042, [Accessed 26.06.2021]

45. Pinquart, M., and Sorensen, S. (2000). Influences of socioeconomic status, social network, and competence on subjective well-being in later life: A meta-analysis. Psychological and Aging, 15(2), 187-224

46. Precupetu, I. (2016). Strenuous objective life circumstances and subjective responses: perceptions of well-being when living in poverty and precarious prosperity in Romania. Calitatea vieţii, 27(2), 99-117.

47. Rasiah, R.R. V, French, J.A. and Khalid, C.S. (2011) The Economics of Happiness: Investigating the Demographic Drivers of Happiness among Generation Y Adults. pp. $1-16$.

48. Stutzer, A. and Frey, B.S. (2004) Does Marriage Make People Happy, Or Do Happy People Get Married? Journal of Socio-Economics.

49. Sumner, L. (1999). Welfare, happiness, and ethics. Oxford: Oxford University Press.

50. Vanhoutte, Bram. Measuring Subjective Well-Being: A Review. 2012.

51. Winkelmann, R. (2009). Unemployment, social capital, and subjective well-being. Journal of Happiness Studies, 10, pp. 421-430. 
52. Wyshak, G. (2016). Income and Subjective Well-Being: New Insights from Relatively Healthy American Women, Ages 49-79. PLoS ONE, 11(2), 1-16. https://doi.org/10.1371/journal.pone.0146303, [Accessed 09.07.2021]

Table1 Descriptive statistics for the variables in the model

\begin{tabular}{|l|c|}
\hline Variable & Total \\
\hline & Mean \\
\hline Life satisfaction & 7.7830 \\
\hline Age & 67.4866 \\
\hline Income & 270,7301 \\
\hline No. of children & 2,2402 \\
\hline & Proportion \\
\hline Marital status & \\
\hline Married/ Cohabitating & 71,48 \\
\hline Widowed & 21,95 \\
\hline Separated/ Divorced & 6,57 \\
\hline Living arrangements & 16,77 \\
\hline Living alone & 83,23 \\
\hline Living with a family member & \\
\hline Level of education & 14,87 \\
\hline Elementary school or less & 56,87 \\
\hline Middle school or unfinished high school & 23,77 \\
\hline Completed high school or post-secondary & 4,49 \\
\hline University studies & \\
\hline Employment status & 70,18 \\
\hline Retired & 13,48 \\
\hline Employed & 16,34 \\
\hline Other inactive & 72,95 \\
\hline Living area & 27,05 \\
\hline Rural & 43,22 \\
\hline Urban & 56,78 \\
\hline Disability & 21,18 \\
\hline No & 25,41 \\
\hline Yes & 41,66 \\
\hline Self-assessment of health & 9,77 \\
\hline Poor & \\
\hline Fair & \\
\hline Good & \\
\hline Very good & \\
\hline Excellent & \\
\hline & \\
\hline
\end{tabular}

